\title{
Lactomega Softgels: For Overall Human Health Helps to Prevent Risk of Chronic Diseases
}

Govind Shukla, C. Subrahmanyam, Dipashree Yajnick, Mantipally Yamuna \& C.J. Sampath Kumar

Lactonova Nutrition Research Centre, Hyderabad.

A Unit of Lactonova Nutripharm (P) Ltd., 81/3, IDA Mallapur, Hyderabad, Telangana-500 076, India.

Copyright: () 2022 Govind Shukla et al. This is an open access article distributed under the terms of the Creative Commons Attribution License, which permits unrestricted use, distribution, and reproduction in any medium, provided the original author and source are credited. omega-3 fatty acids reduce inflammation and may help lower risk of chronic diseases such as heart disease, cancer, arthritis etc Omega-3 fatty acids are highly concentrated in the brain and appear to be important for cognitive (brain memory and performance) and behavioral function. In fact, infants who do not get enough omega-3 fatty acids from their mothers during pregnancy are at risk for developing vision and nerve problems. Symptoms of omega-3 fatty acid deficiency include fatigue, poor memory, dry skin, heart problems, mood swings or depression, and poor circulation. This present paper emphasizes the role of Lactomega soft gels for overall human health.

\section{Introduction}

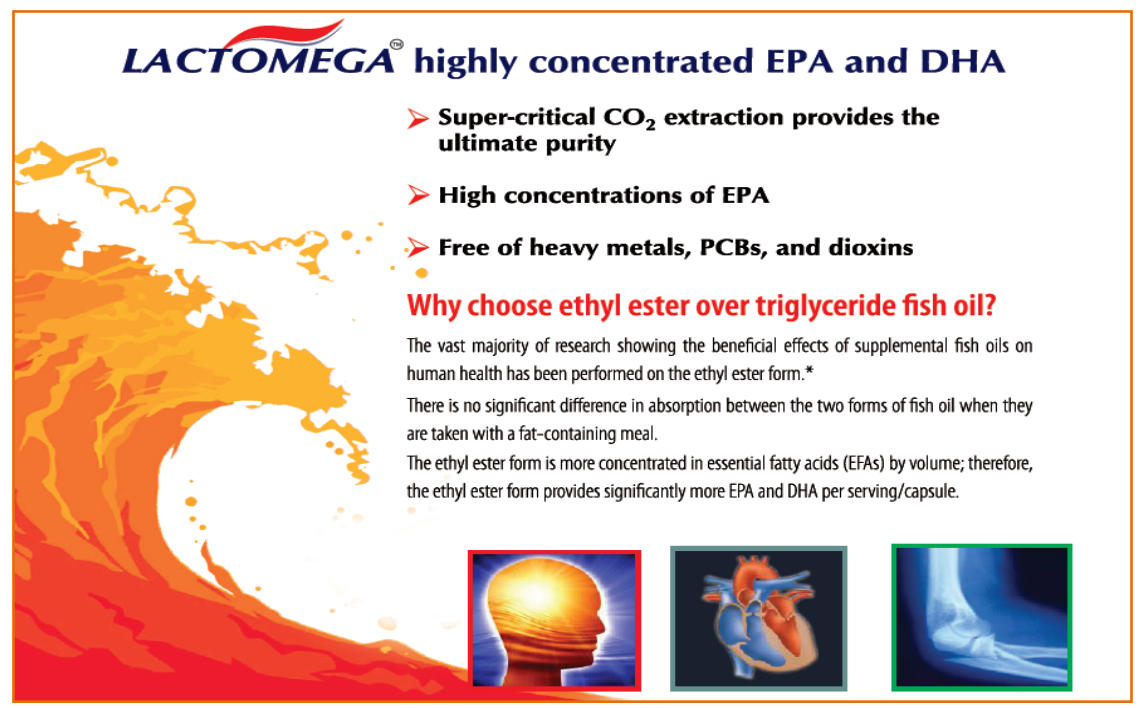

Fish oil is oil derived from the tissues of oily fish. Fish oils contain the omega-3 fatty acids eicosapentaenoic acid (EPA), and docosahexaenoic acid (DHA), precursors of certain eicosanoids that are known to [1]-[2] have health benefits. Fish do not actually produce omega-3 fatty acids, but instead accumulate them by consuming either microalgae or prey fish that have accumulated omega-3 fatty acids, together with a high quantity of antioxidants such as iodide and selenium, from microalgae, where these antioxidants are able to protect the fragile polyunsaturated lipids from peroxidation [3]-[5].

Fatty predatory fish like sharks, swordfish, tilefish, and albacore tuna may be high in omega-3 fatty acids. Marine and freshwater fish oil varies in contents of arachidonic acid, EPA and DHA [8]. Various species range from lean to fatty and their oil content in the tissues has been shown to vary from $0.7-15.5 \%$ [9]. They also differ in their effects on organ lipids [8]. Studies have revealed that there is no relation between total fish intake and estimated omega3 fatty acid intake from all fish and serum omega3 fatty acid concentrations [10]. Only fatty fish intake, 
particularly salmonid, and estimated EPA + DHA intake from fatty fish has been observed to be significantly associated with increase in serum EPA + DHA [10].

The omega-3 fatty acids in fish oil are thought to be beneficial in treating hyper triglyceridemia, and possibly beneficial in preventing heart disease [11]. Fish oil and omega-3 fatty acids have been studied in a wide variety of other conditions, such as clinical depression [12]-[13], anxiety [14]-[16], cancer, macular degeneration, although benefit in these conditions remains to be proven [11].

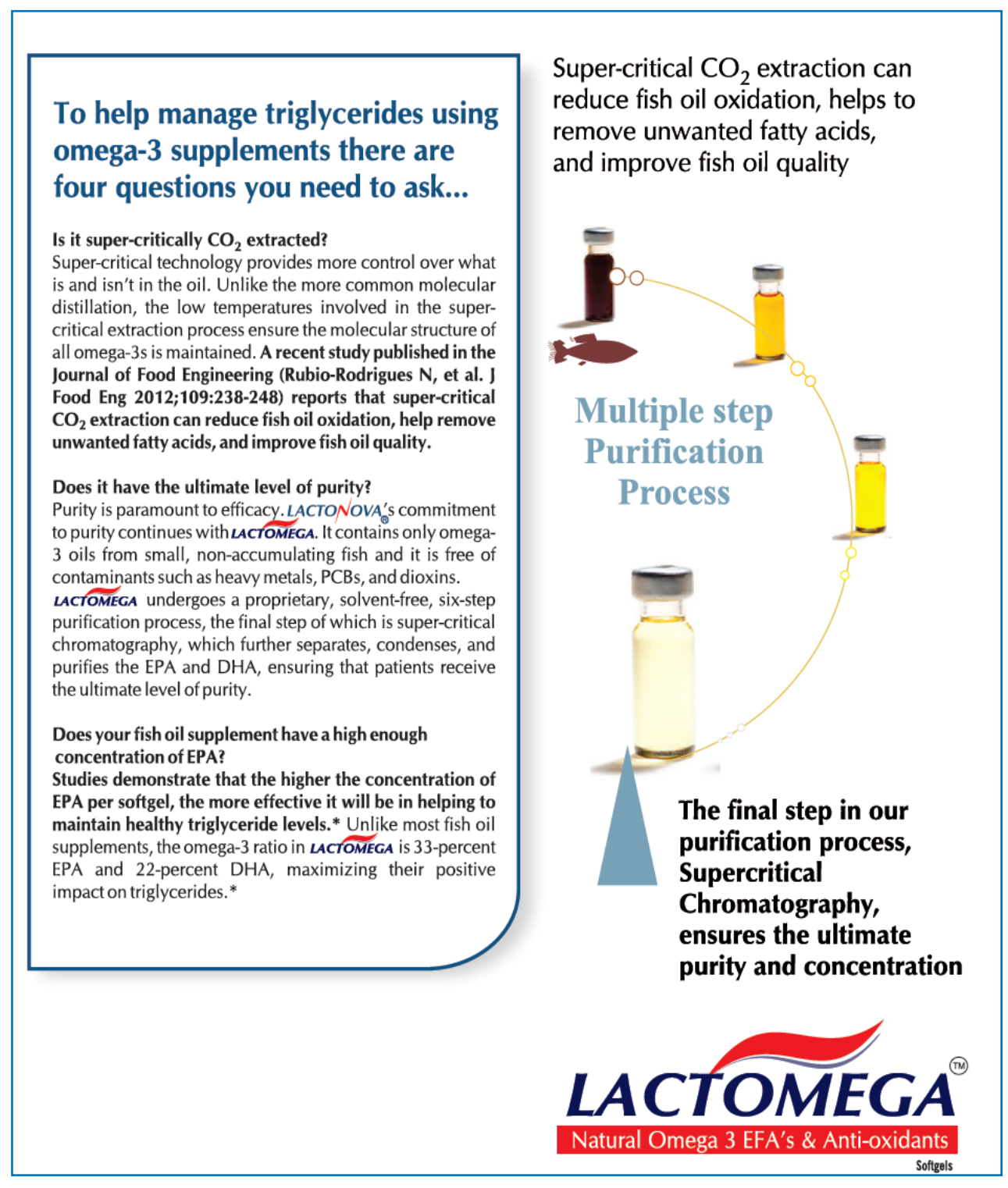

\section{LACTOMEGA softgels}

LACTOMEGA Soft gels contains Ultrapure-Concentrated EPA (Eicosapentanoic acid) and DHA (Decosahexanoic acid), easy to swallow soft gel capsules that promotes cardiovascular health, promotes a healthy immune response, supports joint function and mobility, provides natural vitamin $\mathrm{E}$ and $\mathrm{C}$, potential antioxidants, promotes healthy cognitive function.

Studies show that during pregnancy, Omega-3 fatty acids in LACTOMEGA are required to prevent premature rupture of cervical membrane and thus prevent pre-term delivery. Also, it improves brain development in fetus. 


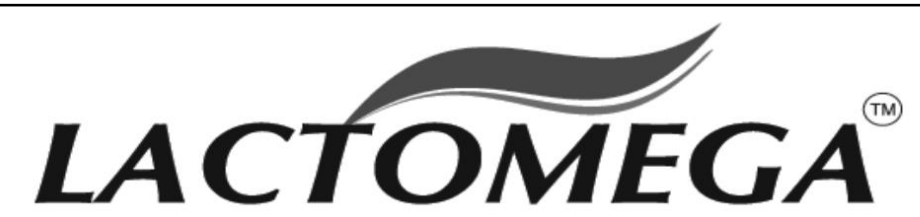

Natural Omega 3 EFA's \& Anti-oxidants

Softgels

\begin{tabular}{|l|}
\hline \\
Serving size : 1 Softgel
\end{tabular}

Ingredients :

Ultra purified fish oil (Containing Omega 3 fatty acids), Alpha tocopheryl acetate,

Capsule shell (Gelatin, Glycerin, Sorbitol, Methyl paraben, Propyl paraben,

Purified water).

\section{Instruction :}

If you are taking any prescribed medication or have any medical conditions always

consult doctor or healthcare practitioner before taking vitamins or supplements.

\section{Suggested use :}

One softgel per day or as directed by the healthcare practitioner.

\section{Storage :}

Store in a cool, dry \& dark place. Keep out of reach of children.

Dietary Supplement. Not for medicinal use.

Packing : 2x15 softgel in blister pack.

\section{Health benefits of Lactomega softgels}

\section{Cancer}

Several studies report possible anti-cancer effects of n-3 fatty acids found in fish oil (particularly breast, colon and prostate cancer) [21]-[23]. Among n-3 fatty acids (omega-3), neither long-chain nor short-chain forms were consistently associated with reduced breast cancer risk. High levels of docosahexaenoic acid, however, the most abundant n-3 polyunsaturated fatty acid (omega-3) in erythrocyte membranes, were associated with a reduced risk of breast cancer [24]. A recent study of 35,000 middle-aged women found that the women who took fish oil supplements had a $32 \%$ lower risk of breast cancer, although the authors stress the result is preliminary and falls short of establishing a causal relationship [25]. Omega-3 fatty acids reduced prostate cancer growth, slowed histopathological progression, and increased survival in genetically engineered mice [26]. However the effects of fish oil consumption by humans on prostate cancer is not conclusive [27]. There is a decreased risk with higher blood levels of DPA, but an increased risk of more aggressive prostate cancer with higher blood levels of combined EPA and DHA [28]. 


\section{Cardiovascular}

The American Heart Association recommends the consumption of $1 \mathrm{~g}$ of fish oil daily, preferably by eating fish, for patients with coronary heart disease although pregnant and nursing women are advised to avoid eating fish with high potential for mercury contaminants including mackerel, shark, or swordfish [29]. Note that optimal dosage relates to body weight.

The US National Institutes of Health lists three conditions for which fish oil and other omega-3 sources are most highly recommended: hypertriglyceridemia, secondary cardiovascular disease prevention and high blood pressure. It then lists 27 other conditions for which there is less evidence. It also lists possible safety concerns: "Intake of 3 grams per day or greater of omega-3 fatty acids may increase the risk of bleeding, although there is little evidence of significant bleeding risk at lower doses. Very large intakes of fish oil/omega-3 fatty acids may increase the risk of hemorrhagic (bleeding) stroke" [11].

There is also some evidence that fish oil may have a beneficial effect on some forms of cardiac dysrhythmia [30]-[31]. A 2008 meta-study by the Canadian Medical Association Journal found fish oil supplementation did not demonstrate any preventative benefit to cardiac patients with ventricular arrhythmias [32]. A 2012 meta-analysis published in the Journal of the American Medical Association, covering 20 studies and 68680 patients, found that fish oil supplementation did not reduce the chance of death, cardiac death, heart attack or stroke [33].

\section{Hypertension}

There have been some human trials that have concluded that consuming omega-3 fatty acids slightly reduces blood pressure (DHA could be more effective than EPA). It is important to note that because omega-3 fatty acids can increase the risk of bleeding, a qualified healthcare provider must be consulted before supplementing fish oil [34].

\section{Mental health}

Studies published in 2004 and 2009 have suggested that the $n$-3 EPA may reduce the risk of depression and suicide. One study [35] compared blood samples of 100 suicide-attempt patients and to those of controls and found that levels of Eicosapentaenoic acid were significantly lower in the washed red blood cells of the suicide-attempt patients. A small American trial in 2009 suggested that E-EPA, as monotherapy, might treat major depressive disorder but failed to achieve statistical significance [36]. Studies [37]-[38] were conducted on prisoners in England where the inmates were fed seafood which contains omega-3 fatty acids. The higher consumption of these fatty acids corresponded with a drop in the assault rates. Another Finnish study found that prisoners who were convicted of violence had lower levels of omega 3 fatty acids than prisoners convicted of nonviolent offenses. It was suggested that these kinds of fatty acids are responsible for the neuronal growth of the frontal cortex of the brain which, it is further alleged, is the seat of personal behavior.

A study from the Orygen Research Centre in Melbourne suggests that omega-3 fatty acids could also help delay or prevent the onset of schizophrenia. The researchers enlisted 81 'high risk' young people aged 13 to 24 who had previously suffered brief hallucinations or delusions and gave half of them capsules of fish oil while the other half received placebo. One year on, only three percent of those on fish oil had developed schizophrenia compared to 28 
percent from those on placebo [39]. A study conducted at Sheffield University in England reported positive results with fish oil on patients suffering from schizophrenia. Participants of the study had previously taken anti-psychotic prescription drugs that were no longer effective. After taking fish oil supplements, participants in the study experienced progress compared to others who were given a placebo [40]-[41].

The largest controlled study to date found no cognitive benefit after two years in the elderly [42]-[43].

\section{Alzheimer's disease}

According to a study from Louisiana State University in September 2005, Docosahexaenoic acid, an omega-3 fatty acid often found in fish oil, may help protect the brain from cognitive problems associated with Alzheimer's disease [44]. A Cochrane meta-analysis published in June 2012 found no significant protective effect for cognitive decline for those aged 60 and over and who started taking fatty acids after this age. A co-author of the study said to Time, "Our analysis suggests that there is currently no evidence that omega-3 fatty acid supplements provide a benefit for memory or concentration in later life" [45].

\section{Lupus}

In a study conducted in Northern Ireland, lupus disease activity, especially in the skin and joints, was significantly reduced in patients who received fish oil supplements at both 12-week and 24-week follow-up periods versus patients who received placebo. There were also changes in the blood platelets of the patients who took the fish oil supplements, with an increase in proteins that are considered anti-inflammatory and a decrease in proteins that promote inflammation; these changes were not evident in the group that took placebo.

The fish oil group showed an increase in flow-mediated dilation, which the researchers took as a sign that the omega-3 oils were helping the cells in the blood vessel walls to remain healthy [46]-[47].

\section{Parkinson's disease}

A study [48] examining whether omega-3 exerts neuroprotective action in Parkinson's disease found that it did exhibit a protective effect in mice. The scientists exposed mice to either a control or a high omega-3 diet from two to twelve months of age and then treated them with a neurotoxin commonly used as an experimental model for Parkinson's disease.

The scientists found that high doses of omega-3 given to the experimental group prevented the neurotoxin-induced decrease of dopamine that ordinarily occurs. Since Parkinson's is a disease caused by disruption of the dopamine system, this protective effect exhibited could show promise for future research in the prevention of Parkinson's disease [48].

\section{Depression}

Evidence regarding the efficacy of fish oil supplements as a treatment for depression is inconclusive. Whereas several methodologically rigorous studies have reported statistically significant positive effects in the treatment of depressed patients, other studies have found effects to be insignificant. In 1999 a team of researchers lead by the Harvard psychiatrist Andrew Stoll published a preliminary placebo-controlled double blind trial which found 
Omega 3 fatty acids "improved the short-term course of illness" of bipolar disorder [49]-[50]. He credits Donald O. Rudin for pioneering this view in 1981 [51]-[52].

A 2003 double blind placebo controlled study published in journal European Neuropsychopharmacology found that among 28 patients with major depressive disorder, "patients in the omega-3 PUFA group had a significantly decreased score on the 21-item Hamilton Rating Scale for Depression than those in the placebo group" [12]. Another study in the American Journal of Psychiatry reported that the addition of fish oil supplements to regular maintenance anti-depression therapy advised "highly significant" benefits by the third week of the trial [16].

A 2005 randomized double-blind placebo-controlled study conducted under the auspices of the New Zealand Institute for Crop and Food Research found "no evidence that fish oil improved mood when compared to placebo, despite an increase in circulating Ï\%o-3 polyunsaturated fatty acids"[53]. Another study published in October 2007 found that fish oil supplements conferred no additional benefits beyond those conferred by standard treatment [54]. However, both of these studies used omega-3 primary consisting of DHA, not EPA.

A 2008 Cochrane systematic review found that limited data is available. In the one eligible study, omega-3s were an effective adjunctive therapy for depressed but not manic symptoms in bipolar disorder. The authors found an "acute need" for more randomised controlled trials [55].

A 2009 metastudy found that patients taking omega-3 supplements with a higher EPA: DHA ratio experienced less depressive symptoms. The studies provided evidence that EPA may be more efficacious than DHA in treating depression. However, this metastudy concluded that due to the identified limitations of the included studies, larger, randomized trials are needed to confirm these findings [56].

\section{Psoriasis}

Diets supplemented with cod liver oil have shown beneficial effects on psoriasis [59].

\section{Pregnancy}

Omega-3 polyunsaturated fatty acids (commonly found in fish oil) protect against fetal brain injury and promote fetal and infant brain health [60]. Some studies reported better psycho motor development at 30 months of age in infants whose mothers received fish oil supplements for the first four months of lactation [61]. In addition, five-year-old children whose mothers received modest algae based docosahexaenoic acid supplementation for the first 4 months of breastfeeding performed better on a test of sustained attention.

This suggests that docosahexaenoic acid intake during early infancy confers long-term benefits on specific aspects of neurodevelopment [61]. Docosahexaenoic acid supplementation has also been found to be essential for early visual development of the baby [62].

However, the standard western diet is severely deficient in these critical nutrients. This omega-3 dietary deficiency, a nutrient found in fish oil, is compounded by the fact that pregnant women become depleted in omega-3s, since the fetus uses omega-3s for its nervous system development. Omega-3s are also used after birth if they are provided in breast milk [63]. In addition, provision of fish oil during pregnancy may reduce an infant sensitization to common 
food allergens and reduce the prevalence and severity of certain skin diseases in the first year of life. This effect may persist until adolescence with a reduction in prevalence and/or severity of eczema, hay fever and asthma [64].

Omega-3 fatty acid supplementation is also beneficial to the mother [60]. It has been shown to prevent pre-term labor and delivery [63]. It is recommended that women who are breastfeeding consume fish oil at least twice a week, although the American Heart Association recommends pregnant and nursing women are to avoiding eating fish with high potential for mercury contaminants including mackerel, shark, or swordfish [64].

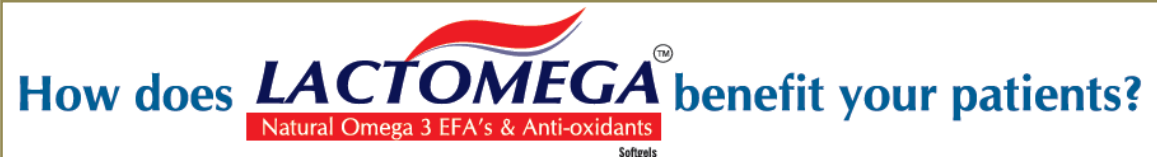

A community study from urban eastern Indian population has shown two-third prevalence rates of metabolic syndrome.*

-D.S. Prasad, Z.Kabir and B.C. Das. Jul-2012

- A 12-week, double-blinded, randomized, placebo-controlled clinical trial found that four grams daily of a 96-percent EPA fish oil product had a significantly positive impact on triglyceride levels.*

A review of 17 randomized, placebo-controlled clinical trials concluded that omega-3 fatty acids (EPA and DHA) at doses of greater than one gram daily for at least three months resulted in significant positive impacts in the triglyceride levels of patients with metabolic syndrome.* -Lopez-Huertas E. Br J Nutr 2012;107 Suppl 2:S185-S194.

- In a cross-sectional analysis of patients with familial hypercholesterolemia, high serum levels of EPA, but not DHA, were associated with improved lipid profiles.* -Sala-Vila A, Cofan M, Mateo-Gallego R, et al. J Nutr Biochem 2013;24:1604-1608.

- Obesity associated with metabolic syndrome can be associated with unhealthy markers found in the adipose tissue, and is a likely cause of insulin resistance. Omega-3 fatty acids have been shown to have a positive effect on insulin resistance and high-fat diets associated with these markers in fat cells.* Kalupahana NS, Claycombe KJ, Moustad-Moussa N. Adv Nutr 2011;2:304-316,

In a randomized, controlled trial of severely obese, non-diabetic patients, 3.36 grams of omega-3 fatty acids (EPA and DHA) for eight weeks resulted in positive impacts in fat cells.*

Mood disorders that are associated with metabolic disorders such as obesity, diabetes, and insulin resistance show improvement from omega-3 fatty acids.*

- A meta-analysis that included 28 studies of omega-3 fatty acids for various aspects of mood disorders found that EPA was more effective than DHA.* The researchers recommended larger controlled trials to confirm their findings.

- A similar meta-analysis of 15 studies found that studies using an omega- 3 product that was 60 percent or greater EPA (compared to DHA) showed benefit of improving markers associated with mood. The positive studies used $200-2,200 \mathrm{mg} /$ day more EPA than DHA. -Sublette ME, Ellis SP, Geant AL, Mann JJ. J Clin Psychiatry 2011;72:1577-1584

\section{Indications}

Promotes cardiovascular health.

Promotes a healthy immune response.

Supports joint function and mobility.

Potent antioxidants.

Promotes healthy cognitive function. 
Prevent premature rupture of cervical membrane \& thus prevents pre-term delivery. Improves brain development in fetus.

\section{LACTOMEGA softgels plays an important role in Heart Health, Coronary heart disease, Arrhythmias}

Have a beneficial effect on heart rate, a major risk factor for sudden cardiac death.

Reduce risk of arrhythmia, a risk factor for sudden cardiac death.

Reduce triglyceride levels, which is an independent risk factor for coronary artery disease.

Minimize the risk of angina, heart attack, and stroke.

\section{LACTOMEGA softgels helps minimize these symptoms}

Depression.

Schizophrenia.

Developmental coordination disorder/dyspraxia.

Dementia.

Huntington disease.

LACTOMEGA softgels has a positive effect on Brain Cognitive Health and Development

Normal development of the brain, retina (eyes), and nervous system of the fetus.

Cognitive development of infants.

Duration of gestation and infant size at birth.

Postpartum depression.

Alzheimer's disease.

LACTOMEGA softgels provides benefit as Anti-Inflammatory, Joint Pain and Digestion

Reducing tender joints.

Reducing the duration of morning stiffness.

Alleviating symptoms for ulcerative colitis, an inflammatory bowel disease (IBD).

DHA \& EPA influence inflammatory balance.

\section{LACTOMEGA softgels provides benefit in Asthma}

Promote respiratory health \& lesser the effects of oxidative stress for patients who have Asthma.

Low intake of Vitamin E \& omega 3 fatty acids had an increased risk of chronic bronchitis, wheezing and Asthma. 


\section{Dosage}

1-2 Softgel capsules daily.

\section{Declarations}

\section{Source of Funding}

This research did not receive any grant from funding agencies in the public, commercial, or not-for-profit sectors.

\section{Competing Interests Statement}

The authors declare no competing financial, professional and personal interests.

\section{Consent for publication}

Authors declare that they consented for the publication of this research work.

\section{References}

1. Moghadasian, Mohammed H. (2008). "Advances in Dietary Enrichment with N-3 Fatty Acids". Critical Reviews in Food Science and Nutrition48 (5): 402.

2. Cleland, Leslieg; James, Michaelj; Proudman, Susannam (2006). "Fish oil: What the prescriber needs to know". Arthritis Research \& Therapy8 (1): 679.

3. Venturi S, Donati FM, Venturi A, Venturi M (2000). "Environmental iodine deficiency: A challenge to the evolution of terrestrial life?". Thyroid10 (8): 727.

4. Venturi S, Venturi M (2007). "Evolution of Dietary Antioxidant Defences". European Epi-Marker 11 (3): 1.

5. Kupper FC, Carpenter LJ, Mc Figgans GB, et al. (2008). "Iodide accumulation provides kelp with an inorganic antioxidant impacting atmospheric chemistry". Proceedings of the National Academy of Sciences of the United States of America 105 (19): 6954.

6. EPA (2007-01-31). "Fish Consumption Advisories". Retrieved 2007-02-08.

7. FAO: World Review of Fisheries and Aquaculture 2008: Highlights of Special Studies Rome.

8. Innis, SM; Rioux, FM; Auestad, N; Ackman, RG (1995 Sep). "Marine and freshwater fish oil varying in arachidonic, eicosapentaenoic and docosahexaenoic acids differ in their effects on organ lipids and fatty acids in growing rats". The Journal of nutrition 125 (9): 2286.

9. Gruger, E. H.; Nelson, R. W.; Stansby, M. E. (1 October 1964). "Fatty acid composition of oils from 21 species of marine fish, freshwater fish and shellfish". Journal of the American Oil Chemists Society 41 (10): 662-667.

10. Philibert, A; Vanier, C; Abdelouahab, N; Chan, HM; Mergler, D (2006 Dec). "Fish intake and serum fatty acid profiles from freshwater fish". The American journal of clinical nutrition 84 (6): 1299.

11. NIH Medline Plus. "MedlinePlus Herbs and Supplements: Omega-3 fatty acids, fish oil, alpha-linolenic acid". Retrieved 2006-02-14. 
12. Su, Kuan-Pin; Huang, Shih-Yi; Chiu, Chih-Chiang; Shen, Winston W. (2003). "Omega-3 fatty acids in major depressive disorder". European Neuropsychopharmacology 13 (4): 267.

13. Naliwaiko, K.; R.L.F.; Da Fonseca, R.V.; Castilho, J.C.; Andreatini, R.; Bellissimo, M.I.; Oliveira, B.H.; Martins, E.F. et al. (2004). "Effects of Fish Oil on the Central Nervous System: A New Potential Antidepressant?". Nutritional Neuroscience 7 (2). doi: 10.1080/10284150410001704525. PMID 15279495.

14. Green, Pnina; Hermesh, Haggai; Monselise, Assaf; Marom, Sofi; Presburger, Gadi; Weizman, Abraham (2006). "Red cell membrane omega-3 fatty acids are decreased in nondepressed patients with social anxiety disorder". European Neuropsychopharmacology 16 (2): 107.

15. Yehuda, Shlomo; Rabinovitz, Sharon; Mostofsky, David I. (2005). "Mixture of essential fatty acids lowers test anxiety". Nutritional Neuroscience 8 (4): 265.

16. Nemets, B.; Stahl, Z; Belmaker, RH (2002). "Addition of Omega-3 Fatty Acid to Maintenance Medication Treatment for Recurrent Unipolar Depressive Disorder". American Journal of Psychiatry 159 (3): 477.

17. Falk-Petersen, S., S. et al. (1998). "Lipids and fatty acids in ice algae and phytoplankton from the Marginal Ice Zone in the Barents Sea". Polar Biology 20 (1): 41.

18. "Fish, Levels of Mercury and Omega-3 Fatty Acids". American Heart Association. Retrieved October 6, 2010. 19. Kris-Etherton, Penny M.; William S. Harris, Lawrence J. Appel (2002)."Fish Consumption, Fish Oil, Omega-3 Fatty Acids, and Cardiovascular Disease". Circulation 106 (21): 2747.

20. "Omega-3 Centre". Omega-3 sources. Omega-3 Centre. Archived from the original on 2008-07-18.

21. Augustsson, Katarina; Michaud, Dominique S.; Rimm, Eric B.; Leitzmann, Michael F.; Stampfer, Meir J.; Willett, Walter C.; Giovannucci, Edward (2003). "A Prospective Study of Intake of Fish and Marine Fatty Acids and Prostate Cancer". Cancer epidemiology, biomarkers \& prevention : a publication of the American Association for Cancer Research, cosponsored by the American Society of Preventive Oncology 12 (1): 64.

22. Deckere, E A M (1999). "Possible beneficial effect of fish and fish $n-3$ polyunsaturated fatty acids in breast and colorectal cancer". European Journal of Cancer Prevention 8 (3): 213.

23. Caygill, C P J; Hill, M J (1995). "Fish, n-3 fatty acids and human colorectal and breast cancer mortality". European Journal of Cancer Prevention 4 (4): 329.

24. Pala, V.; Krogh, V; Muti, P; ChajÃ"s, V; Riboli, E; Micheli, A; Saadatian, M; Sieri, S et al. (2001). "Erythrocyte Membrane Fatty Acids and Subsequent Breast Cancer: a Prospective Italian Study". Journal of the National Cancer Institute 93 (14): 1088.

25. Laurance, Jeremy (2010-07-08). "Fish supplements may reduce risk of cancer". The Independent (London). 26. Berquin, Isabelle M.; Min, Younong; Wu, Ruping; Wu, Jiansheng; Perry, Donna; Cline, J. Mark; Thomas, Mike J.; Thornburg, Todd et al. (2007). "Modulation of prostate cancer genetic risk by omega-3 and omega- 6 fatty acids". Journal of Clinical Investigation 117 (7): 1866. 
27. Heinze, VM; Actis, AB (2012 Feb). "Dietary conjugated linoleic acid and long-chain n-3 fatty acids in mammary and prostate cancer protection: a review.". International journal of food sciences and nutrition 63 (1): 66.

28. Chua, Michael E.; Sio, Maria Christina D.; Sorongon, Mishell C.; Morales, Marcelino L. Jr. (May-June 2013). "The relevance of serum levels of long chain omega-3 polyunsaturated fatty acids and prostate cancer risk: a meta-analysis". Canadian Urological Association Journal.

29. "Fish and Omega-3 Fatty Acids". American Heart Association. Retrieved 2007-02-09.

30. Charnock John S (1999). "The role of omega-3 polyunsaturated fatty acid-enriched diets in the prevention of ventricular fibrillation" (PDF). Asia Pacific Journal of Clinical Nutrition 8 (3): 226.

31. Li G-R Sun H-Y, Zhang X-H Cheng L-C, Chiu S-W Tse H-F, Lau C-P (2009). "Omega-3 polyunsaturated fatty acids inhibit transient outward and ultra-rapid delayed rectifier $\mathrm{K}+$ currents and Na+current in human atrial myocytes". Cardiovasc Res 81 (2): 286.

32. Nair, G. M.; Connolly, S. J. (2008). "Should patients with cardiovascular disease take fish oil?". Canadian Medical Association Journal 178 (2): 181.

33. Rizos, E. C.; Ntzani, E. E.; Bika, E; Kostapanos, MS; Elisaf, MS (2012). "Association between Omega-3 Fatty Acid Supplementation and Risk of Major Cardiovascular Disease Events: A Systematic Review and Meta-analysis". Journal of the American Medical Association 308 (10): 1024.

34. http://www.mayoclinic.com/health/fish-oil/NS_patient-fishoil.

35. Huan, M; Hamazaki, K; Sun, Y; Itomura, M; Liu, H; Kang, W; Watanabe, S; Terasawa, K et al. (2004). "Suicide attempt and n-3 fatty acid levels in red blood cells: A case control study in china". Biological Psychiatry 56 (7): 490.

36. Mischoulon, David; Papakostas, George I.; Dording, Christina M.; Farabaugh, Amy H.; Sonawalla, Shamsah B.; Agoston, A. Monica; Smith, Juliana; Beaumont, Erin C. et al. (2009). "A Double-Blind, Randomized Controlled Trial of Ethyl-Eicosapentaenoate for Major Depressive Disorder". The Journal of Clinical Psychiatry 70 (12): 1636.

37. Stephen mihm (2006-04-16). "Does Eating Salmon Lower the Murder Rate?". NY Times. Retrieved 2007-02-08.

38. Gesch, C. B.; Hammond, SM; Hampson, SE; Eves, A; Crowder, MJ (2002). "Influence of supplementary vitamins, minerals and essential fatty acids on the antisocial behaviour of young adult prisoners: Randomised, placebo-controlled trial". The British Journal of Psychiatry 181: 22.

39. Amminger, G. P.; Schafer, M. R.; Papageorgiou, K.; Klier, C. M.; Cotton, S. M.; Harrigan, S. M.; MacKinnon, A.; McGorry, P. D. et al. (2010). "Long-Chain -3 Fatty Acids for Indicated Prevention of Psychotic Disorders: A Randomized, Placebo-Controlled Trial". Archives of General Psychiatry 67 (2): 146.

40. http://www.one-tcn.com/1812/schizophrenia-naturally/. 
Asian Journal of Basic Science \& Research Volume 4, Issue 1, Pages 10-23, January-March 2022

41. Inman, K "Is Fish Oil the Cure" The Independent. Retrieved 1998-05-26.

42. Dangour, AD; Allen, E; Elbourne, D; Fasey, N; Fletcher, AE; Hardy, P; Holder, GE; Knight, R et al. (2010). "Effect of 2-y nâ^’3 long-chain polyunsaturated fatty acid supplementation on cognitive function in older people: a randomized, double-blind, controlled trial". American Journal of Clinical Nutrition 91 (6): 1725.

43. Fish oil 'no benefit' to elderly NHS, 29 April 2010.

44. Lukiw, W. J.; Cui, JG; Marcheselli, VL; Bodker, M; Botkjaer, A; Gotlinger, K; Serhan, CN; Bazan, NG (2005). "A role for docosahexaenoic acid-derived neuroprotectin D1 in neural cell survival and Alzheimer disease". Journal of Clinical Investigation 115 (10): 2774.

45. Sifferlin, Alexandra (June 13, 2012). "Fish Oil Fail: Omega-3s May Not Protect Brain Health After All". Time. Retrieved June 19, 2012.

46. Duffy EM, GK Meenagh, SA McMillan, JJ Strain, BM Hannigan and AL Bell (2004) "The clinical effect of dietary supplementation with omega-3 fish oils and/or copper in systemic lupus erythematosus" The Journal of Rheumatology, 31 (8): 1551.

47. Wright SA, FM O'Prey, MT McHenry, WJ Leahey, AB Devine, EM Duffy, DG Johnston, MB Finch, AL Bell and GE McVeigh (2007) "A randomised interventional trial of Ï\%o-3-polyunsaturated fatty acids on endothelial function and disease activity in systemic lupus erythematosus" Annals of the Rheumatic Diseases, 67: 841.

48. Bousquet, M.; Saint-Pierre, M.; Julien, C.; Salem, N.; Cicchetti, F.; Calon, F. (2007). "Beneficial effects of dietary omega-3 polyunsaturated fatty acid on toxin-induced neuronal degeneration in an animal model of Parkinson's disease". The FASEB Journal 22 (4): 1213.

49. Andrew L. Stoll, MD; W. Emanuel Severus, MD, PhD; Marlene P. Freeman, MD; Stephanie Rueter; Holly A. Zboyan; Eli Diamond; Kimberly K. Cress, MD; Lauren B. Marangell, MD (May 1999)."Omega 3 Fatty Acids in Bipolar Disorder". Archives of General Psychiatry (American Medical Association) 56 (5): 407.

50. Stoll, Andrew L. (2002). The Omega-3 Connection: The Groundbreaking Omega-3 Antidepression Diet and Brain Program. Free Press. ISBN 0-684-87139-4.

51. Baumel, Syd (Fall 2001). "Your Brain on Fats". The Aquarian (The Aquarian Newspaper).

52. Rudin DO (1981). "The major psychoses and neuroses as omega-3 essential fatty acid deficiency syndrome: substrate pellagra". Biological Psychiatry 16 (9): 837.

53. Silvers, K; Woolley, C; Hamilton, F; Watts, P; Watson, R (2005). "Randomised double-blind placebo-controlled trial of fish oil in the treatment of depression". Prostaglandins, Leukotrienes and Essential Fatty Acids 72 (3): 211.

54. Grenyer, B; Crowe, T; Meyer, B; Owen, A; Grigonisdeane, E; Caputi, P; Howe, P (2007). "Fish oil supplementation in the treatment of major depression: A randomised double-blind placebo-controlled trial". Progress in Neuro-Psychopharmacology and Biological Psychiatry31 (7): 139. 
55. Montgomery P, Richardson AJ (2008). Omega-3 fatty acids for bipolar disorder. In Montgomery, Paul. "Omega-3 fatty acids for bipolar disorder (Art. No. CD005169)". Cochrane database of systematic reviews.

56. http://www.jacn.org/content/28/5/525.full.

57. Bloch MH and Hannestad J (2011) ["Omega-3 fatty acids for the treatment of depression: systematic review and meta-analysis"] Molecular Psychiatry.

58. http://www.nlm.nih.gov/medlineplus/druginfo/natural/993.html.

59. Wolters, M. (2005). "Diet and psoriasis: experimental data and clinical evidence". British Journal of Dermatology 153 (4): 706.

60. Zhang, W.; Hu, X.; Yang, W.; Gao, Y.; Chen, J. (2010). "Omega-3 Polyunsaturated Fatty Acid Supplementation Confers Long-Term Neuroprotection against Neonatal Hypoxic-Ischemic Brain Injury Through Anti-Inflammatory Actions". Stroke 41(10). doi: 10.1161/STROKEAHA.110.586081. PMC 3021248. PMID 20705927.

61. Jensen, Craig L.; Voigt, Robert G.; Llorente, Antolin M.; Peters, Sarika U.; Prager, Thomas C.; Zou, Yali L.; Rozelle, Judith C.; Turcich, Marie R. et al. (2010). "Effects of Early Maternal Docosahexaenoic Acid Intake on Neuropsychological Status and Visual Acuity at Five Years of Age of Breast-Fed Term Infants". The Journal of Pediatrics 157 (6): 900.

62. Institute of Medicine, National Academy of Science (2005). Dietary reference intakes for energy, carbohydrates, fiber, fat, fatty acids, cholesterol, protein and amino acids (Macronutrients). The National Academies Press, Washington DC.

63. American Pregnancy Association. N.P., Aug. 2009.

64. Calder, Philip C.; Kremmyda, Lefkothea-Stella; Vlachava, Maria; Noakes, Paul S.; Miles, Elizabeth A. (2010). "Is there a role for fatty acids in early life programming of the immune system?". Proceedings of the Nutrition Society 69 (3): 373.

65. "ConsumerLab.com Finds Quality Problems with Nearly Thirty Percent of Fish Oil Supplements Reviewed; "Fishy" Claims Identified: Softgels and Liquids for Adults, Children and Pets Tested, Including Krill Oil and Algal Oil Supplements".

66. Reviews of Supplements and Health Products Consumer Lab.

67. "Description of the processes in the value chain and risk assessment of decomposition substances and oxidation products in fish oils". Norwegian Scientific Committee for Food Safety. 2011. Retrieved 19 October 2012.

68. Mercury Levels in Commercial Fish and Shellfish (1990-2010) U.S. Food and Drug Administration. Accessed 25 March 2013.

69. "ConsumerLab.com Review: Fish Oil and Omega-3 Fatty Acid Supplements Review (Including Krill, Algae, and Calamari Oil)". ConsumerLab.com. 13 August 2012. Retrieved 19 October 2012. 
70. "ConsumerLab.com Review: Fish Oil and Omega-3 Fatty Acid Supplements Review (Including Krill, Algae, and Calamari Oil): Contaminants in Fish Vs. Supplements: Contaminants in Fish vs. Supplements". ConsumerLab.com. 13 August 2012.

71. "Fish Oil and Your Health". Sea Grant University of Minnesota. Retrieved 2012-12-14.

72. Villani AM, Crotty M, Cleland LG, James MJ, Fraser RJ, Cobiac L and Miller MD (2013) "Fish oil administration in older adults: is there potential for adverse events? A systematic review of the literature" BMC Geriatrics, 13:41. doi:10.1186/1471-2318-13-41.

73. Can you overdose on DHA and EPA? DHA/EPA Omega-3 Institute. Retrieved 4 November 2011.

74. Kantha SS (1987). "Dietary effects of fish oils on human health: a review of recent studies" (PDF). Yale J Biol Med. 60 (1): 37-44.PMC 2590235. PMID 3551346.

75. Paul Lips (2003-05-08). "Hypervitaminosis A and fractures". N Engl J Med 348 (4): 1927-1928.

76. Jess Halliday (2006-04-13). "Dioxins prompt second UK fish oil withdrawal". Retrieved 2007-02-08.

77. "Pollutants found in fish oil capsules". BBC News. 2002-04-06. Retrieved 2007-02-08.

78. International Fish Oil Standards

79. Elisabeth Leamy (2010-03-03). "Lawsuit Raises Fish Oil Supplement Concerns". Retrieved 2010-03-05.

80. "Lawsuit says fish oil supplements contain PCB", San Francisco Chronicle, March 3, 2010.

81. Brustad, Magritt; Sandanger, Torkjel Manning; Andersen, Vegard; Lund, Eiliv (2007). "POP exposure from fish liver consumption and risk of cancer? The Norwegian Women and Cancer Study". Journal of Environmental Monitoring 9(7).

82. Foran SE, Flood JG and Lewandrowski KB (2003) "Measurement of mercury levels in concentrated over-the-counter fish oil preparations: is fish oil healthier than fish?" Arch Pathol Lab Med, 127 (12):1603-1605.

83. Omega-3 fatty acids for nutrition and medicine: considering microalgae oil as a vegetarian source of EPA and DHA. Doughman SD, Krupanidhi S, Sanjeevi CB. Curr Diabetes Rev. 2007 Aug; 3(3): 198-203. 